\title{
MANAGEMENT OF HIV/AIDS COURSE
}

\author{
Foundation for Professional Development and South African HIV Clinicians Society
}

\section{INTRODUCING THE HIV/AIDS COURSE}

The Foundation for Professional Development (FPD), the educational division of the South African Medical Association (SAMA), in association with the South African HIV Clinicians Society, a SAMA Special Interest Group, is offering a course in the management of HIV/AIDS conditions with the support of an educational grant.

Given the current state of knowledge on HIV/AIDS management and the fact that antiretroviral therapy (ART) is now more affordable, it is feasible to approach HIV/AIDS as a chronic medical condition. This implies that all healthcare professionals need to acquire knowledge on the management of this condition as a matter of urgency.

\section{OBJECTIVES}

The objective of the programme is to establish comprehensive training and support for health care professionals in the Southern African region geared at:

- ensuring a critical mass of trained health care professionals within a relatively short time

- providing health care professionals with comprehensive skills in order to enable them to diagnose and manage HIV/AIDS and STDs and all related clinical conditions including referral to specialist and support services

- providing targeted sectors of the health care profession with appropriate and meaningful information to prevent them from becoming infected

-astablishing a support structure that will keep alumni of the programme updated with new developments in the field, and

creating an expanded organised community of health care professionals dedicated to responding to the HIV/AIDS epidemic.

The objective of the course in the management of HIV/AIDS is, through a combination of self-study and the workshop, to enable health care professionals to:

diagnose HIV/AIDS and STDs

- manage and refer HIV/AIDS patients

do counselling in the management of the patient

- empathise with people "living with HIV'

- fulfil their role as health care professionals in community mobilisation

understand vaccine develooment and trials.

\section{COURSE FORMAT}

The course will combine self-study and face-to-face (workshop) tuition.

\section{SELF-STUDY}

Leading national experts will customise a comprehensive easy-to-use self-study manual based on the International AIDS Society's SHARE Programme. The study material will be provided to participants prior to the workshop in order for them to prepare. The study material eliminates the need for supportive textbooks and will include material on:

- basic immunology and physiology

- economic and epidemiological information

- disease management strategies for STDs and HIVIAIDS, including diagnosis, treatment (inclusive of therapy, monitoring efficacy, side-effects, compliance monitoring, primary resistance, drug failure) and referral options

vaccine development and trials

athical considerations surrounding HIV/AIDS testing and management

- counselling (lifestyle, compliance, terminal, pre- and post-test counselling)

- the role of health care professionals in community mobilisation

living, coping and working with HIV.

Participants will need to score 70\% for the multiple-choice questionnaire in order to ensure compliance with the selfstudy requirements of the course.

\section{WORKSHOPS}

The face-to-face tuition will be presented by leading national and international experts and will take place over a 3-day period in the format of outcome-based workshops focusing on the practical integration of the knowledge acquired through the self-study guide. Workshops will avoid a didactic approach and use case studies, roleplaying and interactive methodology.

\section{CERTIFICATION}

Successful participants will be awarded an attendance certificate for the workshop in the Management of HIV/AIDS by the Foundation for Professional Development. 
Both the workshop and the self-study before the workshop will be submitted for accreditation for CPD points. We will keep you informed of any progress. An estimated 36 CPD points might be allocated for the course.

You will never get this opportunity again because the course is heavily subsidised! Further details on cost will soon be released.

Further information on dates and venues will be provided as soon as the demand is established.

\section{REGISTRATION}

Please send completed registration forms to

The Course Co-ordinator

Management of HIVIAIDS Course

Foundation for Professional Development

PO Box 74789

Lynnwood Ridge

0040

Tel: (012) 481-2032/3

Fax: (012) 481-2083

E-mail: foundation@samedical.org

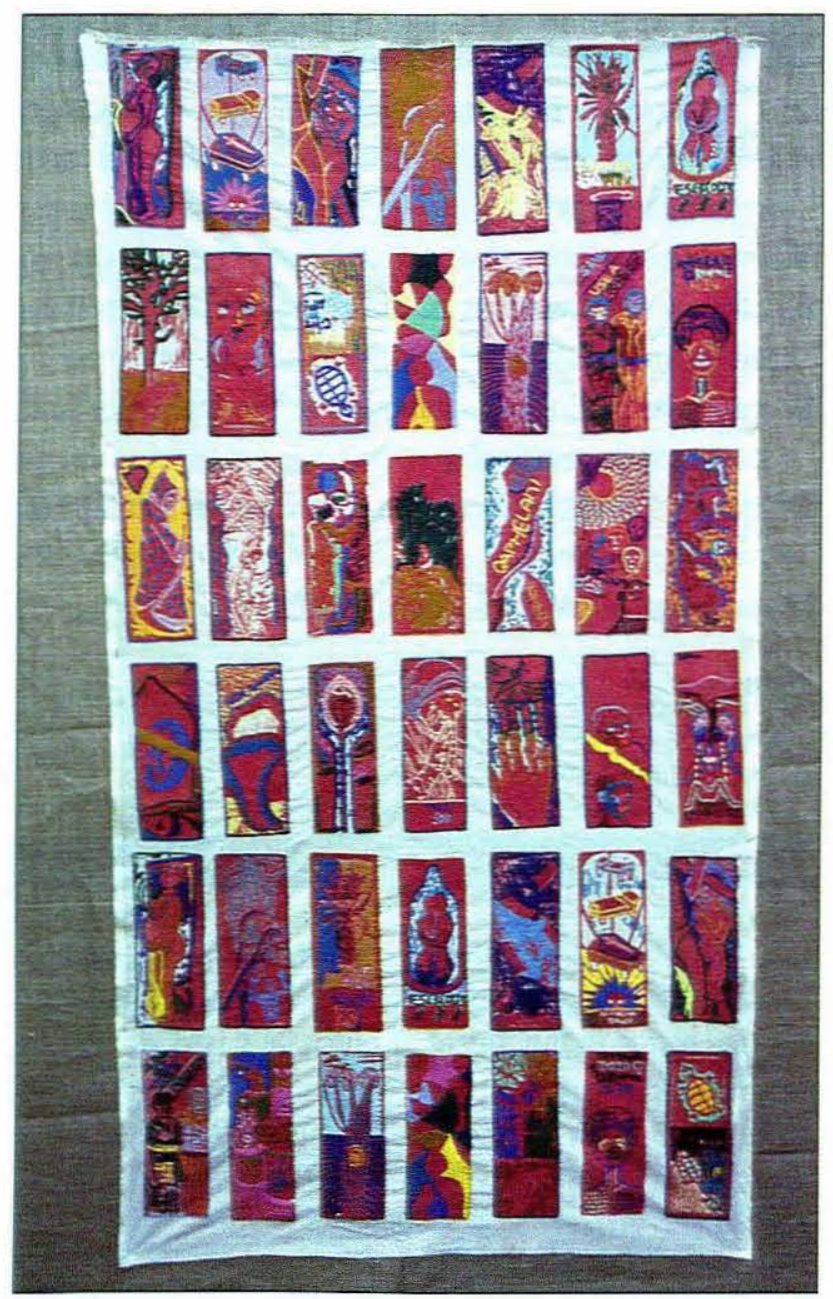

\section{PROPOSED PROVISIONAL WORKSHOP SCHEDULE FOR THE HIV/AIDS COURSE}

\section{TIME}

$08 h 30-09 h 30$

$09 h 30-10 h 00$

$10 h 00-13 h 00$

$13 h 00-14 h 00$

$14 h 00-15 h 00$

$15 h 00-15 h 30$

$15 h 30-17 h 00$

TIME

$08 h 30-09 h 30$

$09 h 30-10 h 00$

$10 h 00-13 h 00$

$12 h 30-14 h 00$

$14 h 00-15 h 00$

$15 h 00-15 h 30$

$15 h 30-16 h 30$

$16 h 30-17 h 00$

\section{TIME}

$08 h 30-09 h 30$

$09 h 30-10 h 00$

$10 \mathrm{~h} 00-13 \mathrm{~h} 00$

$13 h 00-14 h 00$

$14 h 00-15 h 00$

$15 h 00-15 h 30$

$15 h 30-16 h 30$

$16 h 30-17 h 00$

\section{DAY 1 (HIV/AIDS}

overview - conceptualising)

\section{Introduction}

TEA TIME

Basic immunology and physiology of AIDS

\section{LUNCH}

Epidemiological and economic overview

TEA TIME

Clinical management of HIV/AIDS (inclusive of initiation of therapy, monitoring efficacy, side-effects, compliance monitoring, primary resistance, drug failure)

\section{DAY 2 (HIV/AIDS theory in practice)}

The role of health care professionals in community mobilisation

\section{TEA TIME}

Case studies: Participants (in syndicates) are to diagnose (including diagnostic tests), refer and treat (including patient education) in the simulated learning opportunity

LUNCH. Allowance for Jumah prayers to allow Muslim delegates to attend mosque

Case study feedback

TEA TIME

Case study feedback (continue) Summary (overall approach in the management of patients with HIV/AIDS)

\section{DAY 3 (HIV/AIDS reality)}

Vaccine development and trials TEA TIME

Living, coping and working with HIV/AIDS

LUNCH

Ethical considerations surrounding HIV/AIDS testing and management

TEA TIME

Counselling (lifestyle, compliance, terminal, pre- and post-test)

Self-assessment and closure 


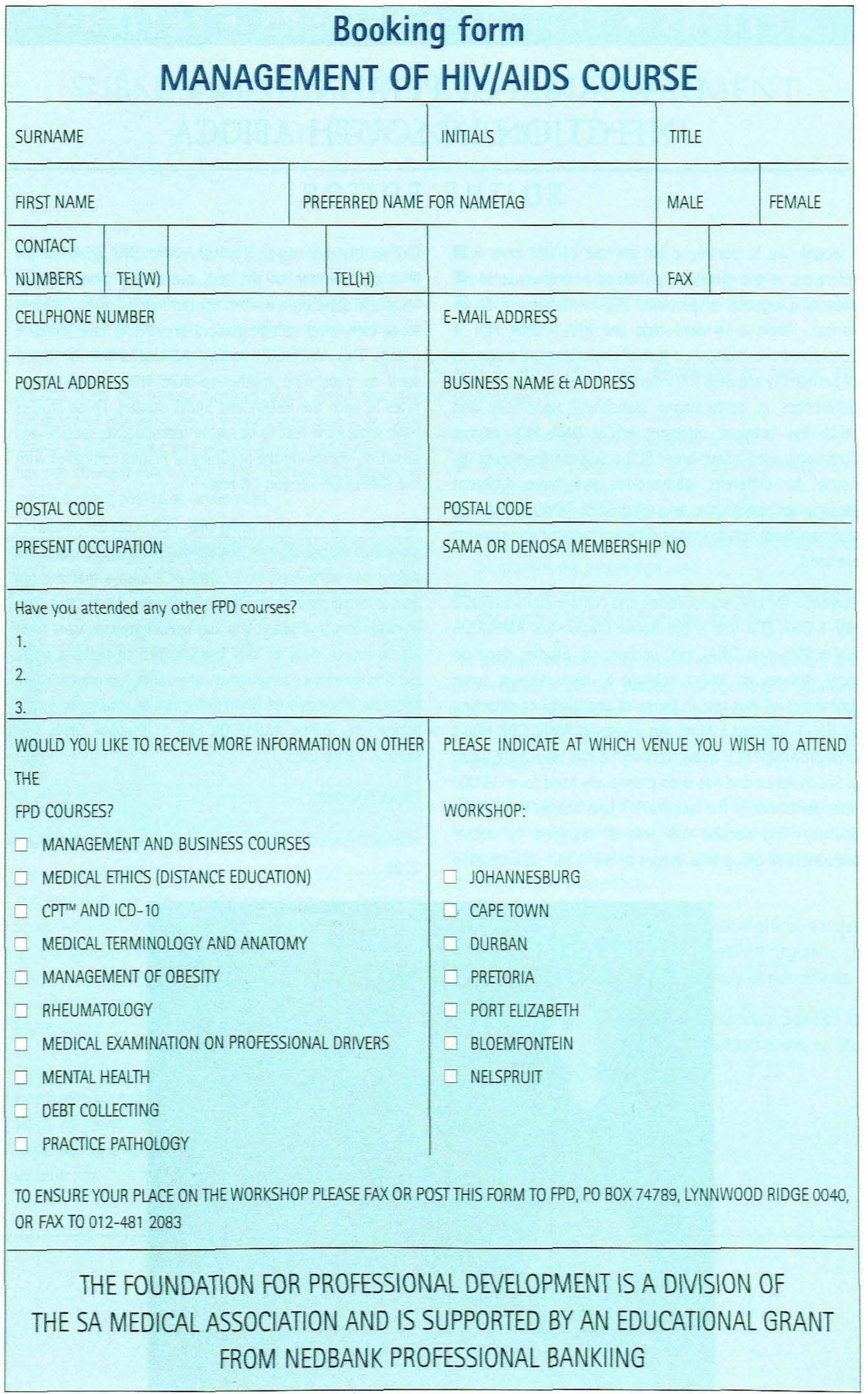

